\title{
A Study to Assess the Knowledge on Pubertal Changes and Menarche among Adolescent Girls Residing in A Selected Rural Community, Kanchipuram District, Tamilnadu
}

\author{
Jyothish Lal Prasad $^{1}$, Abishek, Aishwariya ${ }^{1}$, Ananthi, Cyril Cherian ${ }^{1}$, Reshma Banu ${ }^{1}$, L. Lakshmi ${ }^{2}$ \\ ${ }^{1}$ IV year B.Sc Nursing Students, DR. L. Lakshmi, Professor, Chettinad College of Nursing, Chettinad Academy of \\ Research and Education, Kelambakkam, Kanchipuram dist, Tamilnadu, ${ }^{2}$ Dean, Sathyabama College of Nursing, \\ Sathyabama Institute of Science \& technology, Jeppiaar Nagar, Rajiv Gandhi salai, Semmanchery, Kanchipuram
} District

\begin{abstract}
A study was conducted to assess the level of knowledge on menarche and pubertal changes among adolescent girls residing in a selected rural community. The objectives were to assess the level of knowledge of adolescent girls among menarche and puberty, to find out the association between the level of knowledge on menarche and puberty with selected variables like age, educational status, occupation, and income status .

The sampling technique is non probability convenient sampling technique with the sample of 50 adolescent girls. A Questionnaire was formulated, and used to assess the level of knowledge. The collected data was tabulated and analyzed. Descriptive and inferential statistics were used.

The results were $11 \%$ adolescent girls were having adequate knowledge and 33\% adolescent girls were having moderately adequate knowledge and $6 \%$ of adolescent girls were having inadequate knowledge. So, it shows that more teaching programme to be implement to promote knowledge and hygiene among the adolescent girls. So such research studies will help to increase the knowledge level of the adolescent girls leading to improvement in quality care thereby reducing the mortality rates of reproductive tract infections.
\end{abstract}

Key words: Assess, Knowledge, pubertal changes, menarche and adolescent girls.

\section{Introduction}

Embrace and naturalize Your cycle as a way of nurturing a healthy relationship within yourself as a woman."

- clavel-chapelon F ( 2002)

Puberty is a transitional period between childhood and adulthood, which includes the process of rapid

\section{Corresponding Author:}

Jyothish Lal Prasad,

B.Sc. (Nursing) IVYear, Chettinad College of Nursing, Chettinad Academy of Research and Education, Kelambakkam, Kanchipuram district, Tamilnadu, Email id: jyothishprasad96@gmail.com. growth, development, and maturation in terms of physical, psychological, biochemical, and social conditions. Transition through puberty often begins with the development of external secondary sexual characteristics, which appear as breast enlargement and pubic hair growth in girls. Growth acceleration and peak height velocity occur early in puberty, whereas menarche, the onset of menstrual bleeding ${ }^{1}$.

Menarche is actually the last stage in a complex series of biological developments related to puberty It marks an important point in life for the female adolescent, as it symbolizes the entrance into woman hood 5.Menarche is the first menstrual cycle or menstrual bleeding, in the female human; it is often considered as the central event of female puberty as it signals possibility of fertility ${ }^{4}$. 
In females, menarche is the major landmark of puberty, which usually occurs between 13 and 18 years of age, despite regional and ethnical. Unlike other gradual pubertal changes, menarche signals a dramatic transition from girlhood to womanhood and is recognized as an important transitional point in women's lives .Although menstruation is a natural phenomenon, major psychological changes start with menarche ${ }^{3}$.

\section{Objectives}

1 To assess the level of knowledge of adolescent girls among menarche and puberty

1 To find out the association between the level of knowledge on menarche and puberty with selected variables like age, educational status, occupation, and income status .

\section{Research Methodology}

Research approach used for the study was Nonexperimental evaluative approach. The research design is descriptive research design was adopted for conducting the present study. The study was conducted at a selected village Kanchipuram District, Tamil Nadu with the population of adolescent girls, available in the age group of 13-18 years. The sample size was 50 and Non-probabality sampling technique was used to select the adolescent girls for conducting the study

Selection and Development of Study Instruments

It consisted of two sections.

1. Demographic data of the subjects

2. Structured questionnaires.

PART 1: Demographic variables

It consisted of demographic variables of adolescent girls such as Age, type of family, education, number of siblings, education about puberty

PART 2: Structured interview schedule on knowledge regarding puberal changes and menarche

It consisted of 14 objective type questions. Each question consisted of 4 options. This was framed to assess the level of knowledge on pubertal changes and menarche among adolescent girls

Scoring and Interpretation of the Tool
Structured questionnaires consist of 14 items. The total attainable score was 14 . The cut off score was 8 . Higher the cut off score indicates greater the knowledge level of pubertal changes and menarche

\section{Data Collection Procedure}

The data collection was done for one week at Selected village, Kanchipuram District, Tamil Nadu. Structured questionnaire was used to assess the knowledge level of pubertal changes and menarche. The researchers collected the demographic data and structured questionnaire (SQ) by conducting confidential data of the participants.

\section{Data Analysis}

The data analysis was done using descriptive and inferential statistics. Descriptive statistics like frequency, percentage and mean. Chi-square test was used to find out the association between the pubertal changes and menarche with selected personal information sheet of the pubertal changes and menarche. Collected information on demographic data of pubertal changes and menarche among adolescent girls and Structured questionnaires (SQ) in the form of demographic data of adolescent girls. Descriptive and inferential statistical were used. The mean value is 207 and the standard deviation is 15.62

\section{Study Findings}

Findings of the study were presented based on the objectives

Objective-I: To assess the existing level of knowledge on pubertal changes and menarche among adolescent girls.

Overall mean and SD of adult women related to knowledge aspects were calculated. Adequate knowledge level was $11 \%$, moderate knowledge was $33 \%$, inadequate knowledge level was $6 \%$

From the above discussion, it showed that the mean scores and standard deviation of knowledge aspect has shown a significant difference in the pre test and post test scores.

Objectives II: To associate the existing level of knowledge on pubertal changes and menarche

The association between demographic variables in 
relation with the knowledge aspects of adolescent girls, the findings show that there was no association between demographic variables such as age of adolescent girls, food pattern, educational status, total number of siblings, type of family and source of knowledge

\section{Conclusion}

The number of adolescent girls having moderate knowledge were 33\%, inadequate knowledge were $6 \%$ and adequate knowledge were $11 \%$ and overall mean in knowledge aspects of adolescent girls on pubertal changes and menarche SD of 15.62 . So, health care professionals must organize mass health education programmes about pubertal changes among adolescent gir

\section{Conflict of Interest: Nil}

Sources of Fuding: Self-Funding

Ethical Clearence: Chettinad Academy of Research and Education, Institutional Human Ethics Committee

\section{References}

1. Brunner \& siddarth's from the Text book of Medical Surgical nursing by The health science publisher; 2009.

2. Joyce M.Black, Jane hokanson hawks, from the "Text book of Medical Surgical Nursing", 8th edition ed. India.: Elsevier publishers;

3. Talib HJ, Coupey SM,“conduced a study on Excessive uterine bleeding ;adolescents", medical surgical nursing ed. .

4. Ross and wilson, of the "Textbook of anatomy and physiology", 11th edition ed. new delhi: Elsevier publications; 2009
5. Dorle AS, Hiremath I D, Mannapur B S, Ghattargi $\mathrm{C} \mathrm{H}$ conducted a study on Awareness regarding puberty changes in secondary school children. Journal of clinical and diagnostics research. 2010 .

6. Malleshappa.K, Krishna S, Nandini C. conducted a study on Knowledge and attitude about reproductive health among rural adolescent girls in kuppam mandal, An intervention study. Biomedical research .2011

7. Sheryl. A, Susan. G, Charles .E.conducted a study on Puberty questions asked by early adolescents; What do they want to know, Journal. 2000

8. llesanmi, oluwatoyin olatundun conducted a study on Psychological effects of rural versus urban environment on adolescent's behaviour following pubertal changes. 2010

9. Sharma K Suresh from the textbook of Nursing Research and Statistics.1st ed, Haryana: Rajkamal electric Press; 2011.

10. Saraswathi .C Hunshal, Pujar, H.S, Netravat conducted a study on Reproductive health among rural adolescent girls.karnataka. Journal Agriculture Science. 2010 .

11. Sharma S, Nagar S and Chopra G conducted a study on Health awareness of rural adolescent girls. Journal social science. 2009

12. Nair P, Vijay G 1 , Kannan conducted a study on Awareness and practices of menstruation and pubertal changes among female adolescents in a rural area of east Delhi. Indian Journal of community medicine .2006

13. Singh MM, Devi R, GuptaS.S conducted a study on.Awareness and health seeking behaviour of rural adolescent school girls on menstrual and reproductive health problems. . Indian Journal Medical Science. 2002 